\section{In brief \\ Competition body rules that drug companies "abused" their position}

Green light for drug injecting room: The New South Wales parliament last week authorised a four year extension to the trial of a medically supervised drug injecting room in Sydney. The government expects the room to prevent deaths from overdose among clients and to divert addicts to treatment programmes.

\section{Islamic organisation commits itself to eliminate polio: The World Health Organization has welcomed a commitment from the Organization of Islamic Conferences to try to eliminate polio from countries where the disease is still endemic. WHO said the pledge from the group of 57 countries was extremely important, as six of seven remaining countries where the disease is endemic are members of the organisation: Nigeria, Pakistan, Egypt, Afghanistan, Niger, and Somalia. A Nigerian Islamic organisation had claimed that the vaccine contained anti- fertility substances (BMJ 2003;327:380).}

NICE approves imatinib: The National Institute for Clinical Excellence has announced its recommendations on the use of imatinib for adults with the most common form of leukaemia, the Philadelphia chromosome type. Imatinib should be an option in the most aggressive phase of the illness, it says. See www.nice.org.uk

Whistleblower wins legal battle: Organon, the Dutch

pharmaceutical giant, has chosen not to take the case of whistleblower Dr Koos Stiekema to the Supreme Court. Dr Stiekema won a four year legal battle this summer (9 August, p 307) after an appeal court quashed a $£ 0.5 \mathrm{~m}(\$ 0.8 \mathrm{~m} ; € 0.7 \mathrm{~m})$ damages claim against him from his former employers.

Maternal death rates published: Women in sub-Saharan Africa have a 1 in 16 chance of dying in pregnancy or childbirth, compared with a 1 in 2800 risk for women from developed countries, according to figures from WHO, Unicef, and the United Nations Population Fund.

\author{
Pat Sidley Johannesburg
}

South Africa's competition regulatory body has ruled in favour of AIDS activists who want protection of patents on antiretroviral drugs to be drastically curtailed so that South African makers of generic drugs will be able to produce cheap copies of the drugs.

The Competition Commission ruled in favour of $10 \mathrm{com}-$ plainants (including the trade union federation and several doctors and nurses) who sought to prove that GlaxoSmithKline and Boehringer Ingelheim abused their position of market dominance and their patents by charging too much for their drugs, depriving poor people of access to the drugs.

The activists, grouped under the banner of the Treatment Action Campaign, had also com-

\section{Injury to bile duct during cholecystectomy nearly triples risk of death}

\section{Scott Gottlieb New York}

Patients who have their common bile duct injured during removal of their gall bladder have nearly three times the risk of death in the next few years as patients who do not incur the injury (JAMA 2003;290:2168-73).

Cholecystectomy is the most common elective abdominal surgical procedure in the United States, with 750000 procedures performed each year. Injury to the common bile duct occurs in 1 in 200 of these operations. Repair of the duct is considered a technically challenging procedure and sometimes requires the intervention of specialised surgeons.

Dr David Flum of the University of Washington, Seattle, and colleagues examined the impact of such injury among Medicare beneficiaries who had had a cholecystectomy.

The researchers used data from the Medicare national plained that a voluntary licence that the companies granted to a manufacturer of generic drugs was too restrictive.

The commission ruled that the companies had indeed abused their position and has indicated that all generic drug manufacturers wishing to make cheap copies of antiretroviral drugs ought to be able to do so without seeking the permission of the patent holder.

Just as the commission was making its findings known GlaxoSmithKline announced that it had dropped the prices of several of its antiretroviral drugs and had eased restrictions on the voluntary licence. The company protested that the commission had assured it that it would have time to negotiate a settlement with the litigants. claims history part B (1 January 1992 to 31 December 1999) linked to death records and to the American Medical Association's physician masterfile.

The researchers reviewed records with a procedure code for cholecystectomy and defined as having a common bile duct injury those that were recorded with an additional procedure code for repair of such an injury within 365 days.

Of the 1570361 patients identified as having had a cholecystectomy, $7911(0.5 \%)$ patients had common bile duct injury. Of all the patients who had a chole-

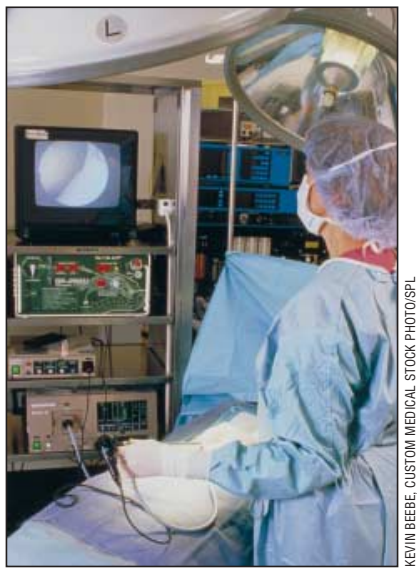

A surgeon removes a patient's gall bladder using a laparoscope
The ruling has been referred to the Competition Tribunal for what is effectively an appeal. It is likely to be vigorously contested, because the precedent set by the commission is likely to affect a wide range of drugs used to treat the types of diseases found in large numbers of poor people in the region. These diseases include malaria and tuberculosis. The lawyer working on behalf of the activists, Fatima Hassan, believes the commission has given a clear indication of its future direction when other such complaints reach it.

In reaching its decision the commission had taken into account international law on intellectual property and had used intellectual property consultants in its research.

South Africa has several generic drug manufacturers, although only two are able to make antiretrovirals. Other companies, however, would be able to import the drugs from India and other countries. cystectomy, 33\% died within the 9.2 year follow up period, with $55 \%$ of patients without the duct injury alive compared with $19.5 \%$ of those who had the duct injury. The adjusted hazard ratio for death during the follow up period was significantly higher (2.79; $95 \%$ confidence interval 2.71 to 2.88 ) for patients with common bile duct injury than for those without. The risk of death increased with increasing age of the patient.

"We also found that improved survival was more likely when a different, more experienced surgeon performed the common bile duct repair, but that $75 \%$ of repair procedures were in fact performed by the same surgeon associated with the injury," Dr Flum said. According to the study, patients had an 11\% increased risk of death if the repairing surgeon was the same as the injuring surgeon $(1.11 ; 1.02$ to 1.20$)$.

The higher the level of experience of the surgeon performing the repair, was also correlated with better survival.

On the basis of the results, the authors recommend that patients with common bile duct injury should be referred to a surgeon and to an institution with greater experience in handling the specialised repair. 